\title{
A shortest route metaheuristic method for oil palm Fresh Fruit Bunch (FFB) transportation based on genetic algorithm: A case study in PTPN III Indonesia
}

\author{
Meilita Tryana Sembiring ${ }^{1, *}$, M Zaky Hadi $^{1}$, Jessica Tanuwijaya ${ }^{1}$, and Irwan Budiman ${ }^{1}$ \\ ${ }^{1}$ Universitas Sumatera Utara, Department of Industrial Engineering, Faculty of Engineering, 20155 Medan, North Sumatera, Indonesia
}

\begin{abstract}
Transportation plays a vital role in palm oil industry supply process because it provides the opportunity to continuously create supply operational efficiency and improve supply chain performance. The objective of this paper is to optimize route transportation process to represent a capacitated shortest route problem in palm oil FFB. A metaheuristic method based on genetic algorithm is designed as a model solution for the mathematical model. A case study in PTPN III Indonesia is presented to test the model effectivity and efficiency. The results indicate that the proposed metaheuristic method can find a better route rather than random method used by the company.
\end{abstract}

\section{Introduction}

Transportation plays a significant role in oil palm FFB industry to ensure quality keeping, continuity, and reduce cost from procurement operational. The problem of real-world network transportation system is complex. Real-world transportation network can consist of millions of nodes connected by a complicated set of edges, making them NP-Hard complex problem. In palm fruit FFB, the guarantee FFB quality has become urgent need to solve problem that keeps Crude Palm Oil quality, improves the procurement process performance, increase the company competitive advantages and keep the continuity and sustainability of palm oil business. To achieve those goals the company must optimize the transportation operation process so that the system can run efficiently.

There are several problems in transportation of Fresh Fruit Bunches (TBS), which is to keep Free Fatty Acid (FFA) level which is directly related to the quality of Crude Palm Oil (CPO) itself, the capacity and continuity of processing Palm Oil Mill (PKS), Fresh Fruit Bunches (TBS) quality keeping in the field, and minimum transportation costs [1]. If the transportation of Fresh Fruit Bunches (TBS) is not optimal, there will be a delay in transporting Fresh Fruit Bunches (FFB) to Palm Oil Factory (PKS) so that the transportation objective (right quality, quantity, place, time and cost) will not be achieved. Transport delays are closely related to the quality of the FFA itself. One of the causes of FFA is the over-ripe fruit, the cause of over ripe itself is the bad handling and operational in the field that is not transported due to lack of transportation in the plantation transportation process. [2]. To solve the problem, it is necessary to determine the route and delivery scheduling [3].
Many researches have been proposed in capacitated inventory routing problem for many cases. In agricultural transportation system, there are several researches proposed by [4], [5], [6], [7]. However, for each agricultural product, they have unique characteristic related to seasonal, bulky, and quickly perishable. Hence, not all model can implement in agricultural case like FFB transportation problem. There are only 1 research that considering transportation process in palm oil procurement process proposed by [8] for math modelling research in palm fruit transportation but only determining time with binary linear programming. Because this paper only formulated binary linear programming without considering algorithm in model solution, it will not efficient to reach the good solution.

In this research, we model a mixed-integer binary programming to represent a capacitated shortest route problem in palm oil FFB transportation process. A metaheuristic method based on genetic algorithm is designed as a model solution for the mathematical model. A case study in PTPN III Indonesia is presented to test the model effectivity and efficiency.

This paper is constructed as follow first we present a problem description in capacitated vehicle routing problem and define assumption and variable for the transportation problem. Then we present model formulation as the real world FFB transportation problem representation in mixed-integer binary programming. After design the mathematic model we design metaheuristic method based on genetic algorithm as the model solution for optimization formulation. The result is discussed to analyse the model solution with real case in PTPN III Indonesia and the we compare with company proposed approach. We also present the future direction for this research so that we can track the

\footnotetext{
${ }^{*}$ Corresponding author: meilita_tryana $@$,yahoo.co.id
} 
research progress in the palm oil FFB transportation problem

\section{Methodology}

The operation research framework [9] was used in this research to model the palm FFB transportation problem based on metaheuristic approach and solve the model by using genetic algorithm as model solution. The framework is constructed from problem definition, problem formulation, model solution (in this case using GA), implementation and model validation by an example case.

\subsection{The oil palm FFB transportation problem}

The FFB transportation system consist of 4 tiers, there are plantation, transportation process, collecting point and mill plant. The illustration of transportation system is illustrated by Fig 1 .

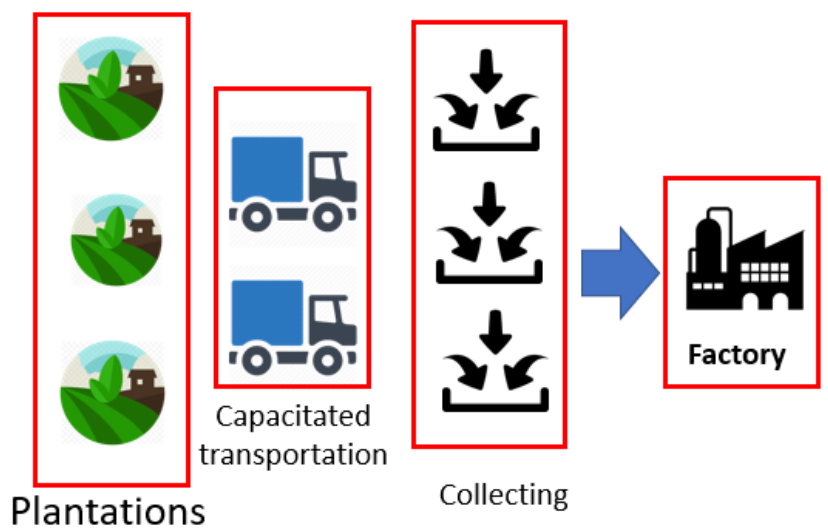

Fig. 1. The illustration of palm FFB transportation system.

The objective of the transportation system aims to minimize the distance and cost. To achieve the objective the operational manager must consider several aspects such as ensure that each plantation is visited only 1 time by vehicle, ensure each dump truck carried FFB in optimal capacity, ensure that all vehicles are not allowed to carry more than their capacity, and choose better route for transportation process. So that the transportation system running with optimal and efficient condition to meet right place, right time, right quantity, right quantity. Those are the NP-hard complex problem that need soft computing approach (i.e. genetic algorithm) to solve the problem. The soft computing approach can tolerance uncertainty, partial truth, imprecision, and approximation with near optimum value can reached with fast calculation. So, this is the challenge for this study to define the formulation and solve it in efficiency way.

Determination of distribution route is determined by considering the value of distance and capacity of transportation equipment used in distributing raw material of fresh fruit bunches (FFB). Merger plantation in one route starts from the greatest distance saving value, but with respect to the total load carried. Merging routes are considered feasible if the combined total load is smaller than the carrying capacity of the transportation mode. This case called capacitated vehicle transportation routing problem

According to the description above, this paper designs optimization formulation with the following assumptions on the palm oil FFB transportation system under study are made in this paper as follow:

- The transportation type for shipping operation used in the system are same

- Allow all transportation mode to visit each plantation

- Work processes in transportation operation have been standardized

- The top-level operation process considered in this study are collecting from plantation and transporting it to a factory for CPO processing

- Palm oil company has its own garden and collecting point after post-harvest process

The notation used in this paper is defined as follow

Table 1. The notation used in this paper.

\begin{tabular}{|c|c|}
\hline Notation & Description \\
\hline$C_{i j}$ & $\begin{array}{c}\text { Cost for travelling process from } \\
\text { node } i \text { to node } j\end{array}$ \\
\hline$X_{i j k}$ & $\begin{array}{c}\text { Binary variable for route } \\
\text { selection in travelling process } \\
\text { from node } i \text { to node } j \text { using } \\
\text { transportation } k\end{array}$ \\
\hline$d_{i j}$ & Distance from node $i$ to node $j$ \\
\hline$w_{k}$ & Capacity of transportation $k$ \\
\hline$i$ & $\begin{array}{c}\text { Index for departure node } \\
(\mathrm{i}=1,2,3, \ldots, \mathrm{I})\end{array}$ \\
\hline$j$ & $\begin{array}{c}\text { Index for arrival node } \\
(\mathrm{j}=1,2,3, \ldots, \mathrm{J})\end{array}$ \\
\hline$k$ & $\begin{array}{c}\text { Index for transportation mode } \\
(\mathrm{k}=1,2,3, \ldots ., \mathrm{K})\end{array}$ \\
\hline
\end{tabular}

\subsection{A problem formulation for oil palm FFB transportation problem}

The objective function for the problem is to minimize total cost of transportation process $C_{i j}$ for each selected transportation route $X_{i j}$ formulated as (1)

$$
\min z=\sum_{i=1}^{I} \sum_{j=1}^{J} C_{i j} \sum_{k=1}^{K} X_{i j k}
$$

With constraint (2)

Each plantation visited only by 1 truck formulated as

$$
\sum_{i=1}^{I} \sum_{k}^{K} X_{i j k}=1
$$

The following constraint is control constraint to ensure each node that has been visited by a truck, the 
truck must depart from the node to visit next node. This formulation is modified from travelling salesman concept (ensure each node is visited). The idea is difference between total selected arrival edge to a node and total departure edge from the node is 0 formulated as (3)

$$
\sum_{i=1}^{I} x_{i j k}-\sum_{j=1}^{J} x_{i j k}=0
$$

The next constraint is a constraint that allow each truck departs only once from the palm oil mill, formulated as (4)

$$
\sum_{j=1}^{J} x_{o j k}=1
$$

The following formulation is a constraint formulation that all vehicles should not carry FFB exceeds its capacity, formulated as (5)

$$
\sum_{k=1}^{K} \sum_{i=1}^{I} \sum_{j=1}^{J} w_{k} x_{i j k} \leq W
$$

\subsection{Model Solution: A heuristic algorithm for oil palm FFB transportation problem based on Genetic Algorithm}

A heuristic algorithm based on genetic algorithm is used as the model solution for palm oil FFB transportation. The genetic algorithm genetic algorithm (GA) is a metaheuristic inspired by the process of natural selection that belongs to the larger class of evolutionary algorithms (EA). Genetic algorithms are commonly used to generate high-quality solutions to optimization and search problems in soft computing and NP-Hard complex problem by relying on bio-inspired operators such as mutation, crossover and selection [10]. The genetic algorithm framework is illustrated by Fig 2 .

The gene in this case is a representation of the palm oil mill which is the starting place for distribution and plantations which is a place to visit by truck, in other words the gene is the point of a graph. The gene representation used in this paper is illustrated by Fig 3 .

Generating the initial population by generating several individual chromosomes randomly to form a unit of population. Individual generation is accompanied by generate individual capacity. Generating individual capacity is done with the purpose of route sharing based on dump truck capacity.

The objective function from problem formulation is the fitness function for evaluating chromosome in genetic algorithm. Each chromosome that give lower fitness function has probability has the possibility of surviving for the next generation.

This paper uses a rank approach for selection process. The ranking selection function is to randomly select chromosomes from the population to serve as parent. The parent will be in the process of cross over process with other selected chromosomes. This method mimics the roulette approach where each chromosome occupies a circle on the wheel according to the proportion of its fitness value rank.

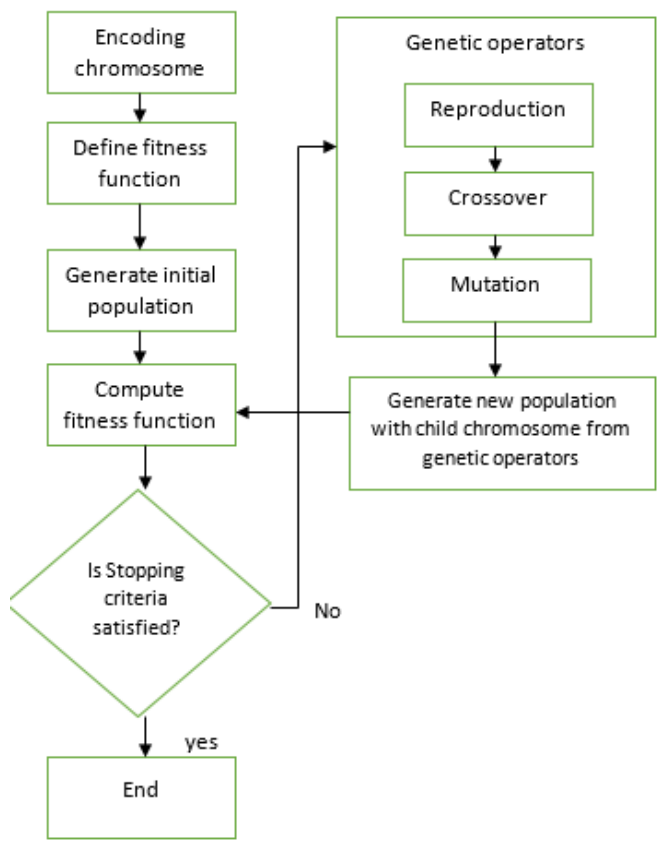

Fig. 2. The typical procedures of Gas [5].

\begin{tabular}{l|l|l|l|l|}
\hline P1 & P2 & P3 & $\cdots . .$. & Pn \\
\hline
\end{tabular}

Fig. 3. A chromosome representation for the transportation problem which contain gene that representing plantation point (P).

The objective function from problem formulation is the fitness function for evaluating chromosome in genetic algorithm. Each chromosome that give lower fitness function has probability has the possibility of surviving for the next generation.

This paper uses a rank approach for selection process. The ranking selection function is to randomly select chromosomes from the population to serve as parent. The parent will be in the process of cross over process with other selected chromosomes. This method mimics the roulette approach where each chromosome occupies a circle on the wheel according to the proportion of its fitness value rank.

After selection process for parent chromosomes, the next process is cross-over process which redeem gene value between two parents. The crossover process produces new chromosome for next generation. This crossover is implemented with a crossover order scheme approach.

Each parent pair produces a pair of children for the next generation selection process to get the same number of populations. The crossover process is determined by Pc (Probability Crossover) and the probability value of the parent pair. Each parent pair will be assigned a random number $[0,1]$, if the probability of the parent pair is less than $\mathrm{Pc}$ then crossover and vice versa. If no crossover occurs, then the child for the next generation is the parent. 
After the crossover process, the child generated from the process will then be processed into the mutation stage. The mutation scheme used is swapping mutation. For all the genes present, if the random number generated $[0,1]$ is less than the specified mutation probability, then the gene value will be exchanged with another randomly selected gene value. The mutation process is performed on crossover children with the aim of obtaining new individuals as candidate solutions in the next generation with better fitness, and eventually towards the desired optimum solution. The crossover and mutation are illustrated by Fig 4.

After the previous step, then the next population is formed in the second generation. The best individual with the highest fitness score in the initial population is brought to the next population, this process is called elitism. The process of elitism aims to keep the highestrated individual fitness not lost during the evolutionary process.

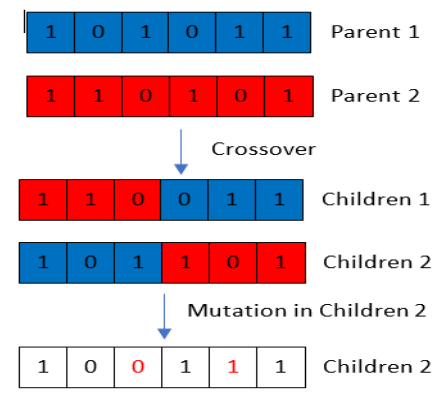

Fig. 4. Illustration of crossover and mutation [11].

\subsection{Implementation and model testing: A real case industrial transportation problem in PTPN III}

PT. Perkebunan Nusantara III (PTPN III) is included in one of 14 State-Owned Enterprises (SOEs) in Indonesia located in kebun rambutan, Tebing Tinggi, Sumatera Indonesia. PT. Perkebunan Nusantara III is engaged in oil palm and rubber plantation business. To produce Crude Palm Oil (CPO) The raw materials used are palm oil derived from plantations managed by PTPN III. The company has 8 plantations to support CPO milling process.

Fresh fruit bunches (TBS) transportation system in PTPN III Kebun Rambutan is carried by dump truck vehicle. The distribution and scheduling of dump trucks for the transport of FFB is based on the work plan from engineering department. Route determination is determined by the dump truck driver by choosing a short distance to reach the plantation. Because it is only intuition, each driver will have different decisions in determining the route of his journey so that the impacts arising from the decisions taken by them will also vary.

The process of transporting fresh fruit bunches did not use transportation scheduling and integrated distribution routes where each plantation is visited by a truck where each truck only visits one plantation even the truck carries FFB less than it capacity. The company has 8 dump trucks for the FFB transportation process with the production of FFB around $127330-1152635$ $\mathrm{kg}$ per month, and the cost of logistic in transportation process around IDR 5 150/km.

\section{Result and discussion}

We used the model to test the real case palm oil FFB transportation in real industrial case problem in PTPN III. This paper used MATLAB software to help the model calculation. The first-generation population generated by using MATLAB for the study case is shown by Fig.5. Each row represents chromosome and value represent gene.

After calculated the fitness value of each chromosome using Matlab software, then the best fitness value from the initial population with the fitness value of 0.0141 . Individuals with the best fitness value of the first-generation population will be retained and taken to the next generation. The next step is to do the selection to determine the individual as the parent.

\begin{tabular}{|l|l|l|l|l|l|l|l|l|l|}
\hline & 1 & 2 & 3 & 4 & 5 & 6 & 7 & 8 \\
\hline 1 & 1 & 6 & 3 & 2 & 5 & 8 & 7 & 4 \\
\hline 2 & 1 & 6 & 3 & 2 & 5 & 8 & 7 & 4 \\
\hline 3 & 7 & 3 & 5 & 6 & 4 & 2 & 8 & 1 \\
\hline 4 & 6 & 3 & 5 & 1 & 2 & 8 & 7 & 4 \\
\hline 5 & 5 & 3 & 8 & 1 & 4 & 2 & 6 & 7 \\
\hline 6 & 7 & 4 & 8 & 1 & 2 & 6 & 5 & 3 \\
\hline 7 & 1 & 3 & 4 & 2 & 3 & 8 & 7 & 6 \\
\hline 8 & 6 & 5 & 7 & 3 & 2 & 4 & 8 & 1 \\
\hline
\end{tabular}

Fig. 5. First generation generated by MATLAB.

After the new generation is obtained then the next process is to find the value of new generation fitness with the help of Matlab software. Iteration is performed to get the optimum fitness value and convergent generated certain. Genetic algorithm is a random generator, so each perform the selection process will always produce a different solution. In this case it takes several times experiment in applying genetic algorithm with Matlab software to get the optimum solution, that is by trying some value of population size and number of generation. After several iterations, the convergent curve will achieve as shown in Fig. 6. The convergence value is the optimal value for the transportation problem [12]

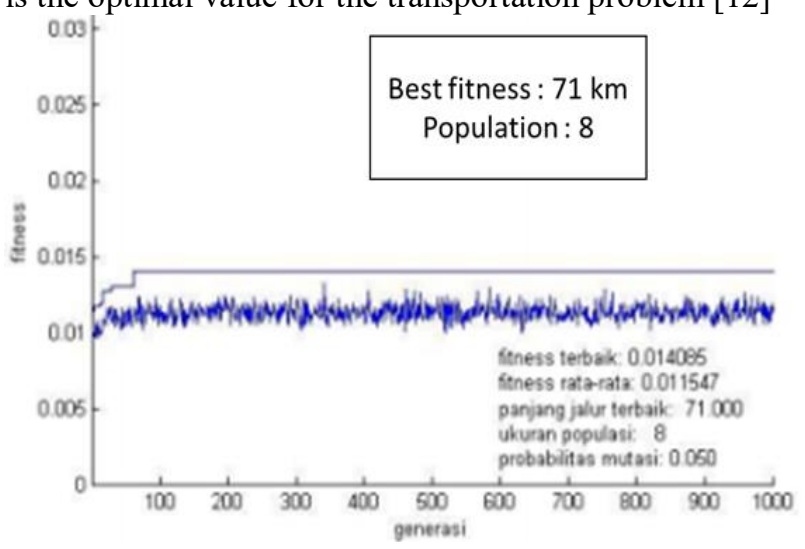

Fig. 6. The convergence curve of GA process after several iterations. 
The solution is from this paper proposed approach using metaheuristic genetic algorithm to solve capacitated transportation problem is illustrated by Fig. 7.

\section{Visualization of the result}

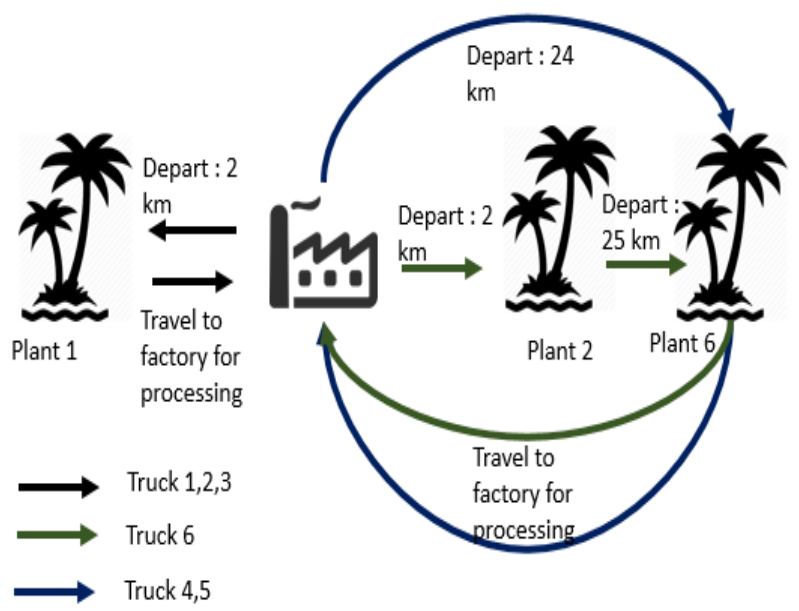

Fig. 7. Illustration the problem solution using GA-based capacitated inventory routing.

As shown in Fig 7. We can determine which route must visit by dump truck to reach it optimal capacity in routing transportation process. Each truck can visit 2 or more plantations; hence the cost of transportation process is lower rather than each truck only visits 1 plantation.

After we get the optimum solution using this paper approach, we compared with company approach and found the different as shown in Fig. 8 and 9

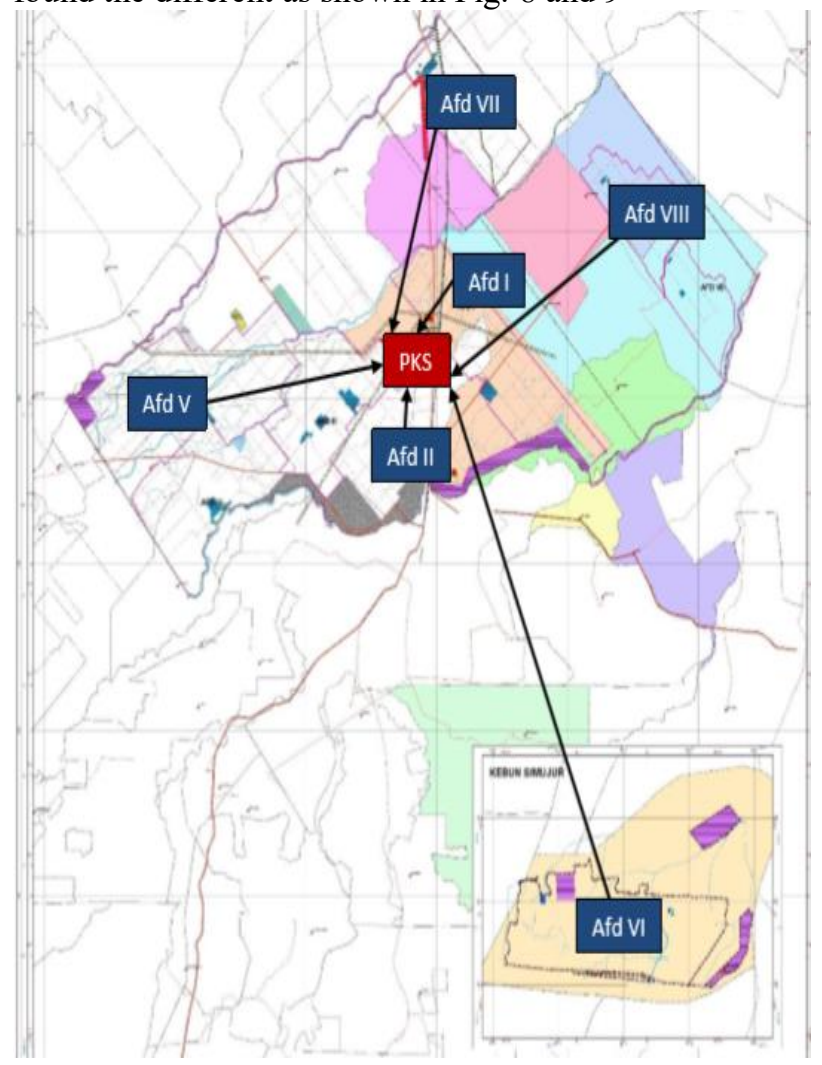

Fig. 8. The company approach capacitated illustration routing.

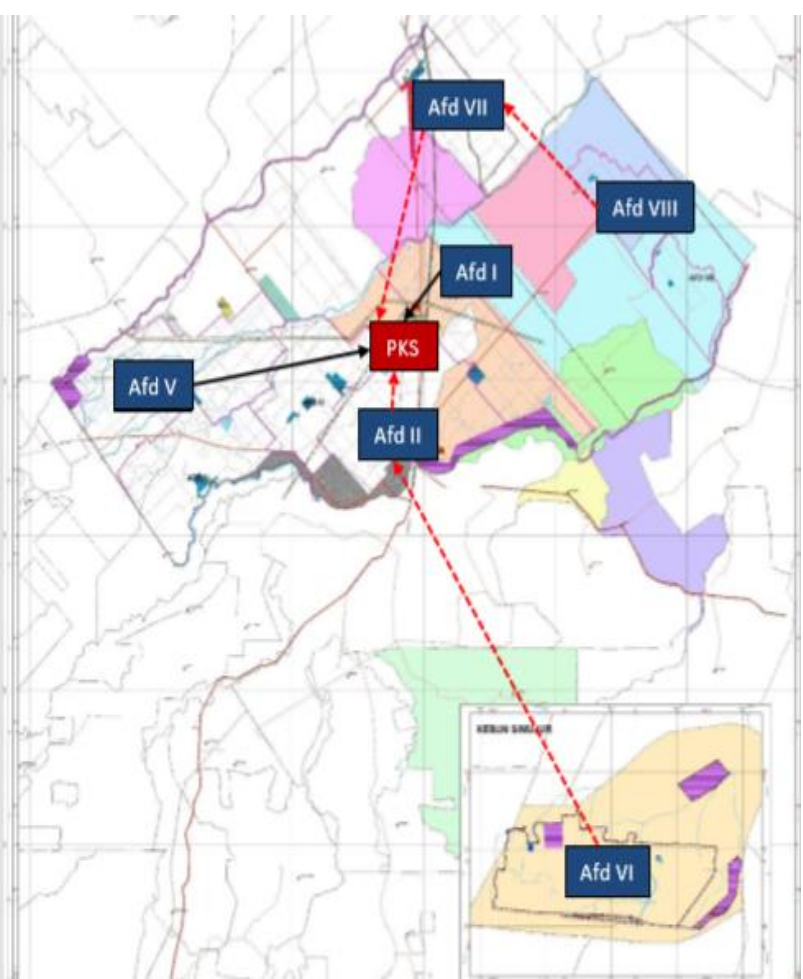

Fig. 9. The proposed approach capacitated vehicle routing.

As shown in Fig 8 and 9 we can conclude that our proposed approach can determine capacitated vehicle routing with respect to vehicle capacity to visit more than 1 plantation $(\mathrm{Afd}=$ plantation, $\mathrm{PKS}=$ Milling factory).

The distance, cost, and truck capacity is tabulated on Table 1.

Table 1. Comparison between proposed approach and company approach.

\begin{tabular}{|c|c|c|}
\hline $\begin{array}{c}\text { Comparison } \\
\text { aspects }\end{array}$ & $\begin{array}{c}\text { Company } \\
\text { approach }\end{array}$ & $\begin{array}{c}\text { Proposed } \\
\text { approach }\end{array}$ \\
\hline Distance & $364 \mathrm{~km}$ & $319 \mathrm{~km}$ \\
\hline Cost per 1 travel & IDR 468680 & IDR 410713 \\
\hline $\begin{array}{c}\text { Capacitated truck } \\
\text { (avg) }\end{array}$ & 8 ton & 10.9 ton \\
\hline
\end{tabular}

Based on the calculation, the genetic algorithm resulted in total distance, cost, and capacitated truck better than the initial state at PTPN III Kebun Rambutan. Thus, it can be said that the solution generated by genetic algorithm is better in solving Capacitated Vehicle Routing Problem (CVRP). Our proposed algorithm approach outperforms the company approach

\section{Conclusion and direction to future research}

In this paper we design a capacitated vehicle routing transportation cost with respect to distance, cost and capacity of the transportation truck. This paper models to represent the FFB transportation problem and design a metaheuristic method based on genetic algorithm as model solution to reach the optimal solution in NP-Hard 
problem of FFB transportation problem. According to the study case, our proposed approach outperforms the PTPN III routing approach in terms of cost, distance and optimal truck loading allocation. The advantages of our proposed approach are can solve NP-Hard complex problem efficiently in capacitated vehicle transportation problem with value respect to uncertainty, approximation, partial truth, and imprecision in such as FFB transportation problem with near optimum value reached. However, the advantages are need additional formulation for different transportation type, only procurement tier logistic analysis, without considering operational level.

According to the disadvantages, we suggest future research in palm oil FFB transportation type with considering other type logistic option, operational level, multi-tier analysis with respect to NP-Hard complex problem, and quality, quantity, time, place and price analysis of FFB transportation

\section{References}

1. M. Makky \& P. Soni, J. of Food Eng. Elsevier E 120, 248-259 (2014)

2. E.H. Alfonso-Lizarazo, J.R. Montoya-Torres, E. Gutiérrez-Franco , App. Math. Mod. Elsevier 37(23), 9652-9664 (2014)

3. C.W. Reeb, T. Hays, R.A. Venditti, R. Gonzales, S Kelley, Bio. Res. 9(3), 5385-5416 (2014)

4. J. I. A. Shunping, P. Hongqin, L. I. U. Shuang, \& X. ZHANG, J. of Trans. Sys. Eng. and Info. Tech., 9(3), 6-16 (2009)

5. A. O. Ajiboye \& O. Afolayan. Int. J. of agri. Eco. and rur. Dev., 2(2), 49-57 (2009).

6. M. L. Li, P. Ramachandran, S. K. Sahoo, S. V. Adve, V. S. Adve, \& Y. Zhou, (2008, March). ACM SIGARCH Comp. Arch. News 36(1), 265-276. ACM, 2008

7. M.S. Oluwole, O.A. Abiodun, Y.D. Masugari. Avai. Onl. In works.bepress.com (2016)

8. R.A. Hadiguna, M. Machfud, J. Tek. Ind. 10(1), 38 (2008)

9. A.H. Taha. "Operation Research : An Introduction Ed. 8". Pearson Education, USA (2008)

10. J.C.H. Pan, P.H. Shih, M.H. Wu, J.H. Lin, Comp. and Ind. Eng., 81, 1-13 (2015)

11. D. Quagliarella \& A. Vicini, "Coupling Genetic Algorithms and Gradient Based Optimization Techniques, Genetic Algorithms and Evolution Strategies in Engineering and Computer Science". JohnWiley \& Sons Ltd., England (1997)

12. F.S. Hillier \& G.J. Lieberman. "Introduction to Operation Research Ed. 3". Mc-Graw Hill USA (2015) 